Irving Lutsky VMD, Margaret Hopwood MA RN, Stephen E. Abram MD, George R. Jacobson PhD, J. David Haddox DDS MD, John P. Kampine MD PhD

\title{
Psychoactive substance use among American anesthesiologists: a 30- year retrospective study
}

The purpose of this study was to assess the cumulative incidence of substance use among anesthesiologists during training and practice, the effect of stress on drug use, and deterrent efficacy of institutional prevention programmes. The 260 anesthesiologists who had trained at the Medical College of Wisconsin between 1958-1988 were surveyed by mail regarding psychoactive substance use. Analysis of 183 responses focused on demographic and psychosocial factors. Substances used most frequently included: alcohol (91.6\%), marijuana (30.8\%) and cocaine (9.4\%). Twenty-nine (15.8\%) anesthesiologists were identified as being substance-dependent: 19 were alcohol-impaired; six were drug-impaired, and four were dependent on both alcohol and drugs. Impairment was more prevalent in anesthesiologists who had completed their training after 1975. Fiftyeight (32\%) anesthesiologists had used illicit drugs to "get high"; 11 acknowledged daily use for two weeks or more, with eight admitting dependency. Substance abuse was more common in parents of impaired anesthesiologists (35.7\%) than in unimpaired colleagues (8.1\%; $P<0.001$ ). The divorce rate for impaired anesthesiologists (24.1\%) was greater than for unimpaired anesthesiologists (5.2\%; $P<0.001$ ). Increased stress during training was not reflected by increased substance use. Few recalled any drug counseling whatsoever. Seventy percent assessed hospital drug control policies as fair or poor. Younger respondents (born after 1951) were more critical of drug control programmes than their older cohort. Incidents of substance abuse were reported for both residents and faculty. Psychoactive substance abuse remains a serious problem among anesthesiologists.

Cette étude avait pour objectif la recherche de la vérité sur la toxicomanie des anesthésistes pendant leur formation et

Key words

ANESTHETISTS: drug abuse.

From the Deptments of Anesthesiology and Psychiatry, Medical College of Wisconsin, Milwaukee, Wisconsin.

Address correspondence to: Professor Irving Lutsky, Chairman, Department of Comparative Medicine, Hebrew University School of Medicine, Jerusalem 91010, Israel. Accepted for publication 30th June, 1993. l'exercice de leur profession lors de périodes de stress et l'efficacité des programmes de prévention. Les 260 anesthésistes formés au collège de médecine du Wisconsin entre 1958 et 1988 ont reçu par la poste un questionnaire sur l'utilisation des drogues psychoactives. Les 183 réponses reçues ont été analysées en tenant compte de facteurs démographiques et psychosociaux. Les produits les plus utilisés ont été dans lordre: l'alcool $(91,6 \%)$, la marijuana (30.8\%) et la cocaïne $(9,4 \%)$. Vingt-neuf anesthésistes sïdentifiaient comme toxicomanes: 19 par l'alcool, six par les drogues, et quatre par les deux substances associées. Les plus grands usagers sont ceux qui ont terminé après 1975. Cinquante-huit (32\%) ont recherché l'effet euphorisant; onze ont reconnu leur utilisation pendant deux semaines ou plus. Huit se disent dépendants. Labus des toxiques était plus fréquent chez les parents des anesthésistes toxicomanes (35\%) que chez les non-utilisateurs $(8,1 \%, P<0.001)$. Le taux de divorces chez les anesthésistes utilisateurs $(24,1 \%)$ était plus élevé que chez les non-utilisateurs $(5,2 \%, P<0.001)$. L'augmentation du stress pendant la formation ne coïncidait pas avec l'utilisation de narcotiques. Peu se sont rappelé d'avoir eu des conseils sur le sujet. Soixante-dix pourcent ont jugé la politique de contrôle hospitalier des narcotiques de moyenne à pauvre. Les plus jeunes parmi les répondants (nés après 1951) étaient plus critiques des programmes de contrôles des narcotiques que leurs confrères plus âgées. Des épisodes d'usage abusif ont été signalées tant chez les résidents que chez les professeurs. L'abus des substance psychoactives demeure un problème dimportance chez les anesthésistes.

The use of psychoactive substances among medical students, ${ }^{1-5}$ residents, ${ }^{6-10}$ and practicing physicians ${ }^{11-15}$ has been well documented. Anaesthesia is recognized among medical specialty groups as having a high risk for the development of chemical dependence. ${ }^{6}$ While in the USA, only $3 \%$ of practicing physicians are anesthesiologists, $13 \%$ of a treated sample of drug-dependent physicians practiced in that specialty. ${ }^{17}$ Although no generally accepted reasons for such over-representation have been put forth, the ease of occupational access to opioids, anaesthetics, and other psychotropic medication has been thought to contribute to this phenomenon. ${ }^{11,18}$ 
In a preliminary report ${ }^{19}$ we described substance abuse in anesthesiology residents as a serious ongoing problem. In order to define further the natural history of this problem, and as an initial step in identifying the variables that may contribute to substance use, questionnaires were mailed to 260 anesthesiologists who had trained at the Medical College of Wisconsin. The survey, approved by the Human Research Review Committee, focused on the use of alcohol and other psychoactive substances. The objectives of this study were: to determine the influence of personal stress on substance use; to assess the impact of institutional drug control policies and educational programmes in deterring substance use; and to determine the prevalence of substance use during training and to relate this to substance use by practicing anesthesiologists.

\section{Methods}

A 55-item multiple choice questionnaire, developed for use in this survey was sent to 260 anesthesiologists who had completed their training at the Medical College of Wisconsin between 1958 and 1988. The questionnaire requested current professional status, socio-demographic information, self-reported past and present patterns of substance use, and a report of perceived substance use by peers and faculty supervisors.

Respondents were assured of anonymity, and questions were formulated so as to preclude identification of individuals. A completed questionnaire was sealed in a blank envelope and inserted into a second previously postmarked envelope to be returned to a rented Post Office Box. Other surveys of drug use have shown that little responses bias occurs when respondents are certain that their anonymity has been safeguarded. ${ }^{20} \mathrm{~A}$ second questionnaire was sent to the same population two months after the initial mailing, along with a revised cover letter requesting participation, if they had not complied previously.

Questionnaire data were compiled on a computerized spreadsheet, and analyzed statistically by chi-square analysis. Three subject groups were analyzed: (1) all respondents; (2) impaired versus unimpaired MD's; and (3) impaired and unimpaired MD's stratified by year of birth (before 1951 and after 1951).

Anesthesiologists were considered drug-impaired, if they met one or more of the following four criteria for drug impairment: (a) acknowledgement that psychoactive drug use, prescribed or not prescribed, had impaired their ability to function professionally; (b) two or more "yes" responses to "CAGE"21 questions concerning drugs; (c) acknowledgement of inpatient and/or outpatient treatment for drugs; or (d) acknowledgement of drug dependence.
TABLE I Demographic information concerning 183 anesthesiologists completing the questionnaire

\begin{tabular}{lcccc}
\hline & \multicolumn{2}{c}{ Unimpaired (154) } & Impaired (29) \\
& $(n)$ & $(n)$ & Impaired & \\
& & & & $P$ \\
\hline Sex & & & & \\
- Male & 128 & 26 & 16.9 & NS \\
- Female & 26 & 3 & 10.3 & \\
Race & & & & \\
- Caucasian & 116 & 25 & 17.7 & NS \\
- Non-Caucasian & 34 & 3 & 8.1 & \\
Decade of birth & & & & \\
- Before 1950 & 98 & 13 & 11.7 & $<0.05$ \\
- After 1950 & 55 & 16 & 22.5 & \\
Country of birth & & & & \\
- USA & 106 & 25 & 19.1 & $<0.05$ \\
- Other & 45 & 3 & 6.3 & \\
\hline
\end{tabular}

TABLE II Substance use in the study population $(n=183)$

\begin{tabular}{lcc}
\hline Population & $(n)$ & $(\%)$ \\
\hline Unimpaired anesthesiologists (non-users) & 154 & 84.2 \\
Impaired anesthesiologists (users) & 29 & 15.8 \\
Serious drug problem & $10^{*}$ & \\
Serious alcohol problem & 23 & \\
\hline
\end{tabular}

*Includes 4 MD's with dual problem (alcohol plus drugs).

Impairment due to alcohol was based on: (a) acknowledgement that alcohol had impaired their professional function; (b) two or more "yes" responses to "CAGE" questions on alcohol; or (c) inpatient and outpatient treatment status for an alcohol problem.

\section{Results}

Over $70 \%$ of the questionnaires sent were returned completed, 147 in reply to the first mailing, and 36 to the second. Completed questionnaires were compared for possible duplication; only five of the 183 returned $(2.7 \%)$ were possible duplicates. Demographic data of the respondents are shown in Table I. Thirty-nine percent of those responding were born after 1951, 79.2\% were Caucasian, and $73.2 \%$ were born in the United States. Men comprised $84.2 \%$ of the sample as compared with the U.S. physician population of $87 \%$ men.

Based on our criteria for impairment, ten anesthesiologists ( $5.5 \%$ of the sample) were identified as drug impaired and $23(12.6 \%)$ were alcohol-impaired. Among the 23 alcohol-impaired anesthesiologists were four who also had drug dependence. Thus, a pooled group of 29 impaired physicians ( $15.8 \%$ of the sample) was identified (Table II).

The rate of divorce among impaired anesthesiologists, $24.1 \%$, was higher than in the unimpaired group, $5.2 \%$ 
$(P<0.001)$ (Table III). The presence of a domestic support system was not different between the two groups, nor did its existence appear to correlate with a lower incidence of substance abuse.

A chronological distribution of the years in which training was completed is shown in Table IV. The percent of impaired physicians who completed their training after 1975 was $19.4 \%$ compared with $11.0 \%$ for those who completed training in 1975 or before. Among 43 anesthesiologists acknowledging the use of illicit drugs (other than barbiturates and tranquilizers), 46.3 initiated their use between the ages of 21 and $25 \mathrm{yr}$ (usual age in medical school).

Alcohol and other drug use patterns were evaluated among the entire sample $(n=183)$. Alcohol use occurred in $91.8 \%, 30.0 \%$ had used marijuana, $9.4 \%$ had used cocaine, $5.6 \%$ had used opioids, $6.1 \%$ had used hallucinogens, $6.7 \%$ had used stimulants, and $5.6 \%$ had used sedative/hypnotics. None had ever used heroin or morphine; nor had they employed PCP, DMT, mescaline, peyote, or psylogical as psychedelics. Comparative rates of use among impaired and unimpaired respondents are displayed in Table V.

When anesthesiologists were asked whether they had ever used drugs to "get high," either without a prescription or in amounts larger than had been prescribed, 58 of 181 survey respondents (32.0\%) replied affirmatively. Among impaired anesthesiologists, $48.3 \%$ used psychoactive drugs not prescribed by a physician. Forty-six (26.3\%) indicated independent use (without prescription) of these drugs more than five times in their lifetimes, while $11 / 172(6.4 \%)$ acknowledged daily use for two weeks or more. Eight of these 11 daily users regularly employed drugs which they had obtained without another physician's prescription, and acknowledged that their need for these substances represented a dependency. The drugs they employed were usually opioids (fentanyl, meperidine and hydrocodone). Four of these eight drugdependent anesthesiologists experienced withdrawal symptoms when they stopped or reduced their use of fentanyl or meperidine. Ten of 29 impaired anesthesiologists stated that they used two or more drugs concomitantly.

Impaired physicians had 8-6 times greater prevalence of history of alcohol and drug problems in one or both parents relative to the unimpaired group (Table VI). A 3.3-fold greater prevalence of alcohol and drug problems in other members of the family was also noted in the impaired group. Impaired physicians also had a 3.9-fold greater prevalence of a family history of mental illness than did the unimpaired physicians. A history of chronic illness was more prevalent, (3.6 times), among parents of impaired anesthesiologists. A family background of
TABLE III Marital history and current domestic status of 183 anesthesiologists

\begin{tabular}{|c|c|c|c|c|}
\hline & \multicolumn{2}{|c|}{$\begin{array}{l}\text { Unimpaired } \\
(n=154)\end{array}$} & \multicolumn{2}{|c|}{$\begin{array}{l}\text { Impaired } \\
(n=29)\end{array}$} \\
\hline & $(n)$ & (\%) & (n) & (\%) \\
\hline \multicolumn{5}{|l|}{ Marital history } \\
\hline Single (never married) & 13 & 8.4 & 1 & 3.4 \\
\hline Married & 131 & 85.1 & 20 & 69.0 \\
\hline Divorced and remarried & 2 & 1.3 & 0 & - \\
\hline Divorced & 6 & 3.9 & 7 & $24.1 \dagger$ \\
\hline Widowed & 2 & 1.3 & 0 & - \\
\hline Separated & 0 & - & 1 & 3.4 \\
\hline \multicolumn{5}{|l|}{ Domestic status } \\
\hline Single with close partner* & 4 & 2.6 & 2 & 6.9 \\
\hline Married* & 128 & 83.7 & 18 & 62.1 \\
\hline \multicolumn{5}{|l|}{ Divorced/separated with close } \\
\hline Living with family member* & 2 & 1.3 & 1 & 3.4 \\
\hline Single without close partner & 11 & 7.2 & 2 & 6.9 \\
\hline $\begin{array}{l}\text { Divorced/separated without } \\
\text { close partner }\end{array}$ & 5 & 3.3 & 2 & 6.9 \\
\hline Other & 0 & - & 1 & 3.4 \\
\hline
\end{tabular}

*Presence of a domestic support system.

$\dagger P<0.001$.

TABLE IV Substance use as related to completion of training

\begin{tabular}{lccc}
$\begin{array}{l}\text { Completion of } \\
\text { anesthesiology training }\end{array}$ & $\begin{array}{l}\text { Unimpaired } \\
(n)\end{array}$ & $\begin{array}{l}\text { Impaired } \\
(n)\end{array}$ & $\begin{array}{l}\text { Impaired } \\
(\%)\end{array}$ \\
\hline Before 1960 & 4 & 1 & 20.0 \\
$1961-1965$ & 14 & 3 & 17.6 \\
$1966-1970$ & 14 & 2 & 12.5 \\
$1971-1975$ & 33 & 2 & 5.7 \\
$1976-1980$ & 25 & 5 & 16.7 \\
$1981-1985$ & 42 & 10 & 19.2 \\
After 1985 & 20 & 6 & 23.1 \\
\hline
\end{tabular}

attempted suicide did not appear to be related to selfreported impairment.

The relative importance of various actual and potential problems (personal, financial, or physical) were assessed by respondents for three stages of their professional career: before residency, during residency, and during practice (Table VII). Their greatest concern as medical students involved financial problems (37.0\%) which apparently continued during residency (37.7\%), falling to $24.6 \%$ during practice years. While residents, their greatest areas of concern included financial issues, interpersonal problems at work, marital problems, emotional, psychiatric or behavioural problems, and professional competence (Table VII). Finally, as mature practitioners of their specialty, their major concerns were aging, interpersonal problems at work, marital problems and malpractice. 
TABLE V Substance use as related to impairment

\begin{tabular}{|c|c|c|c|c|c|c|}
\hline & \multicolumn{2}{|c|}{$\begin{array}{l}\text { Unimpaired }(n=154) \\
183-29=154\end{array}$} & \multicolumn{2}{|c|}{ Impaired $(n=29)$} & \multirow{2}{*}{$\begin{array}{l}\text { Alcohol impaired } \\
(n=23)\end{array}$} & \multirow{2}{*}{$\begin{array}{l}\text { Drug impaired } \\
(n=10) \\
(n)\end{array}$} \\
\hline & (n) & $\%)$ & (n) & (\%) & & \\
\hline \multicolumn{7}{|l|}{ Substance } \\
\hline Alcohol & 139 & 90.3 & 29 & 100.0 & 23 & 10 \\
\hline Marijuana & 38 & 25.0 & 16 & 55.2 & 12 & 7 \\
\hline Amphetamines or ritalin & 7 & 4.6 & 5 & 17.2 & 12 & 4 \\
\hline Cocaine & 13 & 8.6 & 4 & 13.8 & 3 & 2 \\
\hline Sedatives (barbiturates and benzodiazepines) & 2 & 1.3 & 8 & 27.6 & 6 & 6 \\
\hline \multicolumn{7}{|l|}{ Opiates } \\
\hline Codeine & 0 & & 2 & 6.9 & 2 & 2 \\
\hline Meperidine $\mathrm{HCl}$ & 0 & & 1 & 3.4 & 0 & 1 \\
\hline Opium & 0 & & 1 & 3.4 & 1 & 0 \\
\hline Hydrocodone & 0 & & 1 & 3.4 & 1 & 1 \\
\hline Oxycodone & 0 & & 1 & 3.4 & 1 & 1 \\
\hline "Other" opioids & 0 & & 1 & 3.4 & 0 & 1 \\
\hline Fentanyl; sufantanil alfentanil & 0 & & 3 & & 2 & 3 \\
\hline Overall opiate use & 0 & 0.00 & 10 & 34.5 & 7 & 9 \\
\hline \multicolumn{7}{|l|}{ Psychedelics } \\
\hline LSD & 6 & 3.9 & 5 & 17.2 & 3 & 3 \\
\hline
\end{tabular}

TABLE VI Relation of familial problems on impairment among 183 anesthesiologists

\begin{tabular}{|c|c|c|c|c|}
\hline & \multicolumn{2}{|c|}{$\begin{array}{l}\text { Unimpaired } \\
(n=154)\end{array}$} & \multicolumn{2}{|c|}{$\begin{array}{l}\text { Impaired } \\
(n=29)\end{array}$} \\
\hline & (n) & (\%) & (n) & (\%) \\
\hline \multicolumn{5}{|c|}{ History of alcohol/drug abuse } \\
\hline None & 114 & 77.0 & 11 & 39.3 \\
\hline Self & 1 & 0.7 & 3 & 10.7 \\
\hline Spouse/significant other & 4 & 2.7 & 2 & 7.1 \\
\hline Child & 1 & 0.7 & 0 & 0 \\
\hline Parent & 12 & 8.1 & 10 & 35.7 \\
\hline Grandparent & 9 & 6.1 & 6 & 21.4 \\
\hline Sibling & 12 & 8.1 & 3 & 10.7 \\
\hline No response & 6 & 4.1 & 1 & 3.6 \\
\hline \multicolumn{5}{|l|}{ History of mental illness } \\
\hline None & 120 & 82.2 & 23 & 85.2 \\
\hline Self & 5 & 3.4 & 0 & 0 \\
\hline Spouse/significant other & 7 & 4.8 & 0 & 0 \\
\hline Child & 2 & 1.4 & 0 & 0 \\
\hline Parent & 4 & 2.7 & 3 & 11.1 \\
\hline Grandparent & 4 & 2.7 & 0 & 0 \\
\hline Sibling & 11 & 7.1 & 1 & 3.7 \\
\hline No response & 8 & 5.2 & 2 & 7.4 \\
\hline \multicolumn{5}{|c|}{ History of chronic illness/handicap } \\
\hline None & 118 & 81.4 & 22 & 78.6 \\
\hline Self & 7 & 4.8 & 0 & 0 \\
\hline Spouse/significant other & 4 & 2.8 & 0 & 0 \\
\hline Child & 2 & 1.4 & 0 & 0 \\
\hline Parent & 6 & 4.1 & 4 & 14.3 \\
\hline Grandparent & 3 & 2.1 & 0 & 0 \\
\hline Sibling & 6 & 4.1 & 4 & 14.3 \\
\hline
\end{tabular}

The increased stress and change in concerns before and during specialty training, however, were not reflected in a concomitant increase in substance abuse. In actuality, the use of marijuana, cocaine and alcohol was reduced during this period (Table VIII).

When asked if drug counseling was considered to have been an important part of their training programme, fewer than $15 \%$ of the anesthesiologists recalled any counseling whatsoever

More than $50 \%$ of the sample population (99 respondents) indicated that while in residency training they had observed fellow residents using psychoactive substances. Thirty-five respondents also noted psychoactive substance use by faculty members whom they judged to be detrimentally affected. Incidents of faculty substance use were more likely to be observed by impaired residents (34.4\%) than by unimpaired residents (16.2\%); however, proportionally these infractions were less frequently reported to the administration by the impaired group (30.0\% vs $68.0 \%)$.

\section{Discussion}

The frequency of alcohol and other drug problems during residency and in medical practice supports the observation that physicians are more at risk for substance use problems than are members of the general population. ${ }^{17,22,23}$ Because of the over-representation of anesthesiologists among substance-abusing physicians in treatment, it is important to determine the causal and correlated variables contributing to that statistic. 
TABLE VII Personal concerns of anesthesiologists at various stages of their careers

\begin{tabular}{lcccccc}
\hline & $\begin{array}{l}\text { Before } \\
\text { residency }\end{array}$ & Rank & $\begin{array}{l}\text { During } \\
\text { residency }\end{array}$ & Rank & $\begin{array}{c}\text { Medical } \\
\text { practice }\end{array}$ & Rank \\
\hline Financial & $37.0 \%$ & 1 & $37.7 \%$ & 1 & $24.6 \%$ & 5 \\
Marital problems & $16.2 \%$ & 2 & $19.1 \%$ & 3 & $29.4 \%$ & 3 \\
Emotional, psychiatric, behaviour & $13.5 \%$ & 3 & $18.5 \%$ & 4 & $17.0 \%$ & 10 \\
Sexual issues & $11.7 \%$ & 4 & $16.8 \%$ & 6 & $20.7 \%$ & 8 \\
Competence & $11.1 \%$ & 5 & $17.9 \%$ & 5 & $19.1 \%$ & 9 \\
Death & $10.6 \%$ & 6 & $9.4 \%$ & 7 & $23.5 \%$ & 6 \\
Alcohol and/or drugs & $9.4 \%$ & 7 & $8.3 \%$ & 8 & $6.7 \%$ & 13 \\
Interpersonal work problems & $7.8 \%$ & 8 & $19.7 \%$ & 2 & $31.6 \%$ & 2 \\
Divorce & $4.4 \%$ & 9 & $3.9 \%$ & 11.5 & $11.2 \%$ & 11 \\
Physical problems & $2.2 \%$ & 10 & $6.1 \%$ & 10 & $22.9 \%$ & 7 \\
Malpractice & $2.8 \%$ & 11 & $7.9 \%$ & 9 & $27.7 \%$ & 4 \\
Disciplinary problems & $1.7 \%$ & 12 & $3.9 \%$ & 11.5 & $1.7 \%$ & 14 \\
Legal problems & $1.1 \%$ & 13 & $1.7 \%$ & 14 & $10.1 \%$ & 12 \\
Aging concern & $0.6 \%$ & 14 & $4.4 \%$ & 13 & $32.4 \%$ & 1 \\
\hline
\end{tabular}

TABLE VIII Percent* of anesthesiology residents reporting changes in substance use during training

\begin{tabular}{lllllll}
\hline & \multicolumn{2}{l}{ Substances } & & & & \\
\cline { 2 - 7 } & Alcohol & Marijuana & Cocaine & Sedatives & Stimulants & Opiates \\
\hline Use increased & 5.8 & 0 & 1.3 & 1.8 & 0.6 & 1.2 \\
Use level unchanged & 45.6 & 7.5 & 3.8 & 1.8 & 4.3 & 2.4 \\
Use decreased & 25.1 & 12.5 & 10.8 & 1.2 & 0 & 0.6 \\
No prior or current use & 23.4 & 80 & 84.2 & 95.1 & 95.1 & 95.7 \\
\hline
\end{tabular}

*Percentages based on number of respondents.

Our survey data provides the following profile of an impaired anesthesiologist (IA): a physician, most likely a male Caucasian, born in the United States after 1950, who completed his anesthesiology training after 1975 and has been divorced. He is more likely to have a family history of substance abuse, most often in a parent (35.7\%). This observation coincides with reports of a $39 \%$ rate of parental alcoholism among known alcoholics. ${ }^{23}$ The IA is also more likely to have a family history of mental or chronic illness.

The observation by respondents that substance abuse information and/or counseling appeared to be nonexistent during training is disturbing. Increasing their knowledge and awareness of the problems of impairment may yet prove to be a useful preventive measure. Approximately one-half of those using illicit drugs acknowledged that their substance use was initiated before residency, suggesting that attempts at counseling during residency training might represent an exercise in futility.

Relationships between drugs of choice and accessibility of psychoactive substances are obscure. One survey ${ }^{16}$ suggests that workplace availability of narcotics may make them more attractive to anesthesiologists; fentanyl citrate and unspecified opioids were reported respectively as the first- and second-most widely abused drugs among anesthesiology residents; our data do not confirm this observation. Among our sample of IA's, twice as many used alcohol as their sole substance of abuse, as used drugs alone or in combination with alcohol. Fentanyl, an opioid readily accessible to anesthesiologists, was used by $10.3 \%$ of the IA's in our study.

An apparent overall decrease in general drug use in the United States has recently been noted. A survey of the National Institute of Drug Abuse ${ }^{25}$ indicated that the number of Americans using cocaine decreased by half from 1985 to $1988 .{ }^{26}$ The number of people using any illicit drug, including marijuana, declined in that same period from $12 \%$ of the population to $7 \%$. The reduced recreational use of marijuana and cocaine by anesthesiologists in our survey would appear to parallel this general trend. With drugs closely associated with the practice of anaesthesiology, e.g., fentanyl, a greater use level was seen among the anesthesiologists in our survey than reported in the general public. ${ }^{24}$

The cumulative incidence of psychoactive drug and/ or alcohol-associated impairment in our survey was $15.8 \%$. This is comparable to addiction rates for physicians previously reported. ${ }^{23}$ None of the 183 respondents 
had ever been asked to surrender a medical license or a controlled substance registration. None had ever had a medical certificate or license suspended, nor had any experienced disciplinary action related to substance abuse. Three physicians among 29 impaired anesthesiologists left anesthesiology; all are still actively practicing, but in other fields of medicine. Two acknowledged that their alcohol and/or drug disability was the primary cause for them leaving anesthesiology, the third indicated that he was merely "seeking another career," but did not indicate that his drug dependence was the motivating reason.

While we may conjecture that an impaired physician can more easily identify a substance-abusing colleague, he may be more reluctant than his unimpaired colleagues to report these infractions. While we do not know how many of the respondents chose to individually confront their substance-using peers, it is known that physicians often fail to act in the case of impaired colleagues. ${ }^{26}$

The structure of our survey instrument may have led to over-enumeration with several respondents reporting the same incident of substance use; thus this occurrence data must be interpreted with some caution. It is disturbing from a standpoint of intervention and recovery that a substantial number of incidents of substance abuse involving residents $(n=63)$ and faculty $(n=20)$ went unreported. While approximately $70 \%$ of the infractions involving faculty members were reported, it was not possible to determine whether these occurred at a social event or in the workplace.

In summary, it appears that substance abuse is a rather common problem among anesthesiologists. About half the anesthesiologists who admitted to impairment had substance abuse problems that began before residency. Alcohol was abused by more respondents than were other substances. Despite admitted impairment by 29 anesthesiologist physicians, none was ever required to surrender a medical license. Thirty-five respondents reported observing faculty members abusing psychoactive substances. The programmes created to identify and treat substance abuse problems during specialty training were perceived by the large majority of respondents as inadequate.

\section{References}

1 Clark DC. Alcohol and drug use and mood disorders among medical students: implications for physician impairment. QRB Qual Rev Bull 1985; 14: 50-4.

2 McAuliffe WE, Rohman M, Fishman P, et al. Psychoactive drug use by young and future physicians. $J$ Health Soc Behav 1984; 25: 34-54.

3 Baldwin DC Jr., Conard S, Hughes P, Achenbach KE, Sheehan DV. Substance use and abuse among senior med- ical students in 23 medical schools. Proceedings of the Annual Conference on Research in Medical Education 1988; 27: 262-7.

4 Kory WP, Crandall $L A$. Nonmedical drug use patterns among medical students. Int J Addict 1984; 19: 871-84.

5 Maddux JF, Hoppe SK, Costello RM. Psychoactive substance use among medical students. Am J Psychiatry 1986; 143: 187-91.

6 Ward $C F$, Ward GC, Saidman $L J$. Drug abuse in anesthesia training programs. JAMA 1983; 250: 922-5.

7 Urbach $J R$, Levenson $J L$, Harbison $J W$. Perceptions of housestaff stress and dysfunction within the academic medical center. Psychiatr Q 1989; 60: 283-96.

8 Conard SE, Hughes $P$, Baldwin D, Achenbach $K$, Sheehan $D$. Substance use and the resident physician: a national study. Proceedings Annual Conference on Research in Medical Education 1988; 27: 256-61.

9 Maddux JF, Timmerman IM, Costello RM. Use of psychoactive substances by residents. J Med Educ 1987; 62: 852-4.

10 Sethi $B B$, Manchanda $R$. Drug abuse among resident doctors. Acta Psychiatr Scand 1980; 62: 447-55.

11 Gallegos KV, Browne CH, Veit FW, Talbott GD Addiction in anesthesiologists: drug access and patterns of substance abuse. QRB Qual Rev Bull 1988; 14: 116-22.

12 Logan WS. The evaluation of the impaired physician. New Dir Ment Health Serv 1989; 41: 33-53.

13 McAuliffe WE, Rohman $M$, Santangelo $S$, et al. Psychoactive drug use among practicing physicians and medical students. N Engl J Med 1986; 315: 805-10.

14 Angres $D H$, Busch $K A$. The chemically dependent physician: clinical and legal considerations. New Dir Ment Health Serv 1989; 41: 21-32.

15 Herrington RE, Benzer DG, Jacobson GR, Hawkins $M K$. Treating substance-use disorders among physicians. JAMA 1982; 247: 2253-7.

16 Menk EJ, Baumgarten RK, Kingsley CP, Culling RD, Middaugh $R$. Success of reentry into anesthesiology training programs by residents with a history of substance abuse JAMA 1990; 263: 3060-2.

17 Talbott GD, Gallegos KV, Wilson PO, Porter TL. The medical association of Georgia's Impaired Physicians Program. JAMA 1987; 257: 2927-30.

18 Lecky JH, Aukburg SJ, Conahan TJ 3rd, et al. A departmental policy addressing chemical substance abuse. Anesthesiology 1986; 65: 414-7.

19 Lutsky II, Abram SE, Jacobson GR, Hopwood M, Kampine JP. Substance abuse by anesthesiology residents. Acad Med 1991; 164-6.

20 Luetgert MJ, Haberman Armstrong A. Methodological issues in drug usage surveys: anonymity, recency, and frequency. Int J Addict 1973; 8: 683-9.

21 Ewing JA. Detecting alcoholism. The CAGE questionnaire. JAMA 1984; 252: 1905-7. 
22 Vaillant GE, Brighton JR, McArthur C. Physicians' use of mood-altering drugs. N Engl J Med 1970; 282: 365-70.

23 Spiegelman WG, Saunders L, Mazze RI. Addiction and anesthesiology. Anesthesiology 1984; 60: 335-41.

24 Herrington $R E$, Jacobson $G R$, Benzer $D G$ (Eds.). Alcohol and Drug Abuse Handbook, St. Louis, Mo: Warren H.

Green Company, 1987.

25 National Institute on Drug Abuse. National Household Survey on Drug Abuse: Population Estimates 1988 (Washington, Dept. of Health and Human Services, \#(ADM)) 1989; 89-1636.

26 Reuben $D B$, Noble $S$. House officer responses to impaired physicians. JAMA 1990; 263 958-60. 